ORIGINAL ARTICLE

\title{
Hep Par 1 expression in carcinoma of the cervix: implications for diagnosis and prognosis
}

\author{
T P Thamboo, A Wee
}

See end of article for authors' affiliations

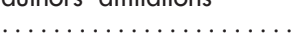

Correspondence to: Dr T P Thamboo,

Department of Pathology, National University of Singapore, National University Hospital, 5 Lower Kent Ridge Road, Singapore 119074, Republic of Singapore; pattpt@nus.edu.sg

Accepted for publication 1 July 2003

\begin{abstract}
Aims: To determine the frequency and pattern of Hep Par 1 expression in cervical carcinomas of various histological types and to correlate expression with prognostic parameters.

Methods: Twenty nine cervical carcinomas were analysed for tumour type, hepatoid and neuroendocrine differentiation, and vascular invasion. A semiquantitative analysis was performed for Hep Par 1, $\alpha$ fetoprotein, chromogranin, and synaptophysin immunoreactivity.

Results: Hep Par 1 expression was seen in seven of the 29 cervical carcinomas (three of seven adenocarcinomas, one of 17 squamous cell carcinomas, one of two adenocarcinomas with adenocarcinoma in situ, one of two adenocarcinomas in situ, and one of one large cell neuroendocrine carcinoma with adenocarcinoma in situ). Normal looking endocervical epithelium was also positive in one case. Cases expressing Hep Par 1, with or without neuroendocrine coexpression, were associated with a higher rate of vascular invasion and a worse prognosis. Three of the five cases expressing neuroendocrine markers also coexpressed Hep Par 1.

Conclusions: Hep Par 1 expression in carcinoma of the cervix is not uncommon and is present in a variety of histological types. Expression of this marker appears to be associated with more aggressive biological behaviour and a worse prognosis. The uterine cervix is another site that may express Hep Par 1 and hence the use of this antibody in situations of diagnostic difficulty, especially involving lesions within the liver, have to be coupled with the knowledge of the range of tissues it may stain.
\end{abstract}

"The cumulative experience with this aberrant staining has lowered the specificity of Hep Par 1 for detecting hepatocyte derived tissues"
In our study, we analysed cervical carcinomas to determine the frequency and pattern of immunohistochemical expression of hepatoid and neuroendocrine differentiation and any correlation with prognosis.

\section{MATERIALS AND METHODS}

Hysterectomies for cervical carcinoma, including consultation cases, diagnosed in the department of pathology, National University Hospital, Singapore, were reviewed from January 1997 to December 2002. All available archival material and medical records were retrieved. Ten hysterectomies for uterine leiomyomata/adenomyosis were included as controls.

Formalin fixed, paraffin wax embedded blocks of the tumour and adjacent non-neoplastic cervical tissue, in addition to normal cervical tissue from the controls, were used for immunohistochemical studies. Immunostaining for Hep Par l was performed with a monoclonal mouse antihuman hepatocyte antibody (Hepatocyte antibody; clone OCHIE5; Dako, Glostrup, Denmark) using the Dako EnVision ${ }^{\circledR}+$ method. Dewaxed and rehydrated $4 \mu \mathrm{m}$ histological sections were heated with Dako target retrieval solution at pH 9.9 for 25 minutes. Endogenous peroxide activity was blocked with 3\% hydrogen peroxide for 10 minutes. The sections were then incubated with Hepatocyte antibody diluted 1/500 for one hour. After washing in Tris buffered saline (TBS) solution for 10 minutes, the sections were incubated with horseradish peroxidase labelled polymer antimouse antibody complex for 30 minutes and then

Abbreviations: AC, adenocarcinoma; AFP, $\alpha$ fetoprotein; AIS adenocarcinoma in situ; CIN3, cervical intraepithelial neoplasia 3; FNA fine needle aspiration; HCC, hepatocellular carcinoma; LCNEC, large cell neuroendocrine carcinoma; SCC, squamous cell carcinoma; TBS, Tris buffered saline 
washed again in TBS solution. Diaminobenzidine chromogen solution was applied and the coloured product was allowed to develop before counterstaining and mounting. Normal liver tissue served as positive controls.

Immunostaining for AFP (Neomarker, Freemont, California, USA), chromogranin (Dako) and synaptophysin (Dako) was also performed using the Dako EnVision ${ }^{\circledR}+$ system.

The microscopic parameters examined were tumour type, histomorphology, and vascular invasion. The tumours were typed according to the World Health Organisation classification. $^{31}$ Hepatoid features included polygonal cells with abundant granular or eosinophilic cytoplasm, trabecular/ solid growth pattern, and bile production. A semiquantitative analysis was performed for Hep Par 1, AFP, chromogranin, and synaptophysin immunoreactivity. The extent (percentage) and the intensity of staining (graded mild, moderate, to strong) were recorded, as were the histological and topographical locations of the positive areas.

\section{RESULTS}

There were 29 cervical carcinoma specimens comprising 17 squamous cell carcinomas (SCCs), seven adenocarcinomas (ACs), two ACs with AIS, one LCNEC with AIS, one AIS, and one AIS with cervical intraepithelial neoplasia 3 (CIN3). The age range of the patients was from 34 to 65 years. The tumour size ranged from 0.7 to $4.8 \mathrm{~cm}$ in maximum dimension. The disease ranged from stage IAl to IIIB (American Joint Committee on Cancer staging)..$^{32}$

Seven of the 29 cervical carcinomas studied were positive for Hep par 1 (table 1).

\section{Histomorphology of the Hep par 1 positive tumours} The Hep Par 1 positive tumours comprised the LCNEC with AIS, three ACs, one AIS with CIN3, one AC with AIS, and one SCC. Only one case (case 5) exhibited hepatoid features in addition to the AC and AIS components. The hepatoid cells were polygonal with ample eosinophilic granular cytoplasm and grew in sheets with no obvious gland formation (fig 1 ); occasional mucin positive signet ring cells were noted. Case 2 was a well differentiated AC, endometrioid type, composed of glands and papillary structures with clear cell areas

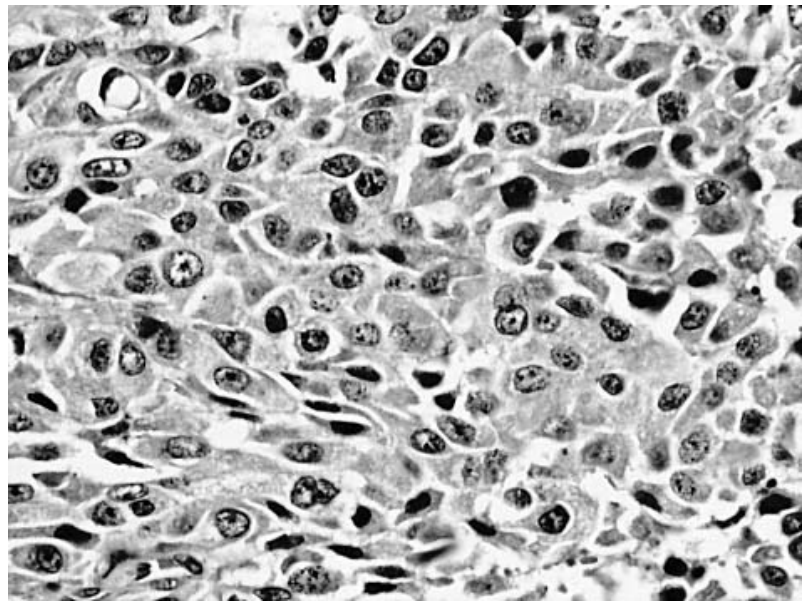

Figure 1 Poorly differentiated adenocarcinoma exhibiting broad cords of large polygonal cells with eosinophilic granular cytoplasm suggestive of hepatoid differentiation (haematoxylin and eosin stain).

reminiscent of fetal gut epithelium. The tumour cells had ample amphophilic to vacuolated cytoplasm and most had large subnuclear and/or apical mucin vacuoles (fig 2 ). Case 1 was the LCNEC characterised by solid sheets of large, highly pleomorphic undifferentiated cells with high mitotic rate occurring in association with AIS (fig 3).

\section{Invasive component}

Four of a total of 27 invasive carcinomas showed moderate to strong Hep Par 1 immunoreactivity, ranging from very focal $(<5 \%$ in case 7$)$ to $100 \%$ (case 2 ) positive cells (fig 4$)$. The SCC showed $50 \%$ staining (fig 5 ).

\section{In situ component}

Three of the five AIS lesions showed Hep Par 1 positivity (fig 6); staining was strong but patchy, ranging from $10-80 \%$ in extent. It was notable that the incumbent invasive components in two of these cases with AIS (cases 1 and 5) were negative.

Table 1 Cervical carcinomas with Hep Par 1 expression

\begin{tabular}{|c|c|c|c|c|c|c|c|c|}
\hline \multirow[b]{2}{*}{ Case } & \multirow[b]{2}{*}{ Tumour type } & \multicolumn{4}{|c|}{$\begin{array}{l}\text { Immunohistochemical markers } \\
\text { (extent of staining) }\end{array}$} & \multicolumn{3}{|c|}{ Clinical correlates } \\
\hline & & HP & AFP & CG & SYN & VI & Stage & Outcome \\
\hline \multirow[t]{3}{*}{1} & LCNEC & - & Focal & ND & Focal & + & $|\mathrm{B}|$ & Liver metastasis \\
\hline & AIS & $80 \%$ & - & - & - & & & \\
\hline & Normal & $80 \%$ & - & - & - & & & \\
\hline \multirow[t]{2}{*}{2} & $\mathrm{AC}$ & $100 \%$ & - & - & - & + & $|\mathrm{B}|$ & $A+W$ \\
\hline & Normal & - & - & - & - & & & \\
\hline \multirow[t]{2}{*}{3} & $\mathrm{AC}$ & $25 \%$ & - & - & - & - & IIIB & $A+W$ \\
\hline & Normal & - & - & - & - & & & \\
\hline \multirow[t]{3}{*}{4} & AIS & $25 \%$ & - & $5 \%$ & - & - & $|\mathrm{B}|$ & $A+W$ \\
\hline & $\mathrm{CIN} 3$ & - & - & - & - & & & \\
\hline & Normal & - & - & - & - & & & \\
\hline \multirow[t]{3}{*}{5} & $\mathrm{AC}$ & - & - & $100 \%$ & $80 \%$ & - & $|\mathrm{B}|$ & DOD \\
\hline & AIS & $10 \%$ & - & $50 \%$ & - & & & \\
\hline & Normal & - & - & - & - & & & \\
\hline \multirow[t]{2}{*}{6} & SCC & $50 \%$ & - & - & - & + & $|\mathrm{B}|$ & DOD \\
\hline & Normal & - & - & - & - & & & \\
\hline \multirow[t]{2}{*}{7} & $A C$ & Focal & - & - & - & + & $|\mathrm{B}|$ & $A+W$ \\
\hline & Normal & - & - & - & - & & & \\
\hline
\end{tabular}

Seven of the 29 cases expressed Hep Par 1 in the form of distinct cytoplasmic granules Normal refers to normal endocervical epithelium.

AC, adenocarcinoma; AFP, $\alpha$ fetoprotein; AIS, adenocarcinoma in situ; $A+W$, alive and well; $C G$, chromogranin; CIN3, cervical intraepithelial neoplasia 3; DOD, dead of disease; HP, Hep Par 1; LCNEC, large cell neuroendocrine carcinoma; ND, not done; SCC, squamous cell carcinoma; SYN, synaptophysin; VI, vascular invasion. 


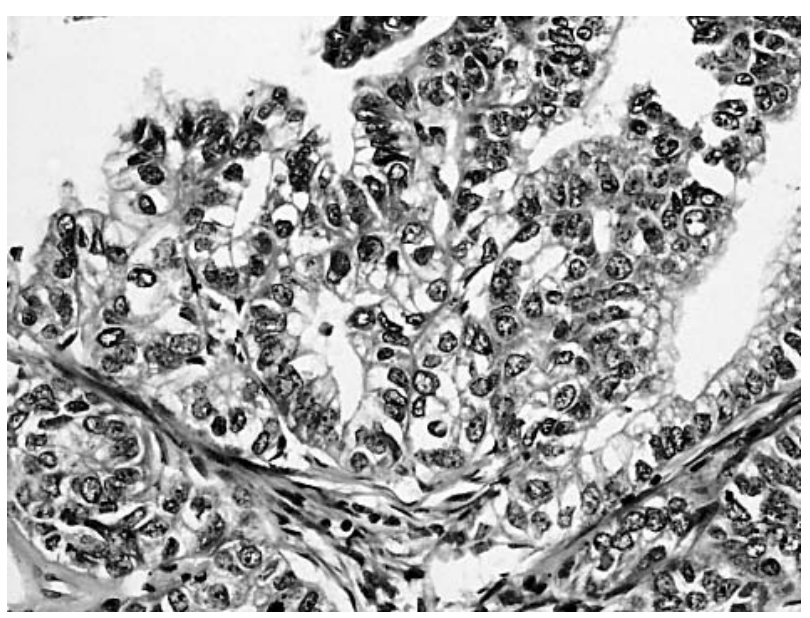

Figure 2 Adenocarcinoma with clear cell features reminiscent of fetal gut epithelium suggesting enteroblastic differentiation (haematoxylin and eosin stain).

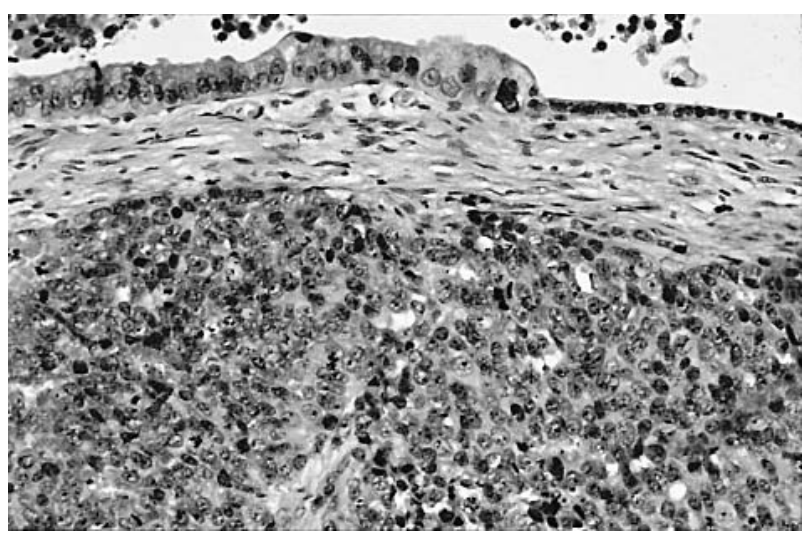

Figure 3 Large cell neuroendocrine carcinoma with coexisting endocervical adenocarcinoma in situ (haematoxylin and eosin stain).

Endocervical epithelium

In case 1, the non-dysplastic looking endocervical glands showed strong Hep Par 1 positivity in addition to the AIS component (fig 7). No staining was detected in the normal epithelium in the other 28 cases.

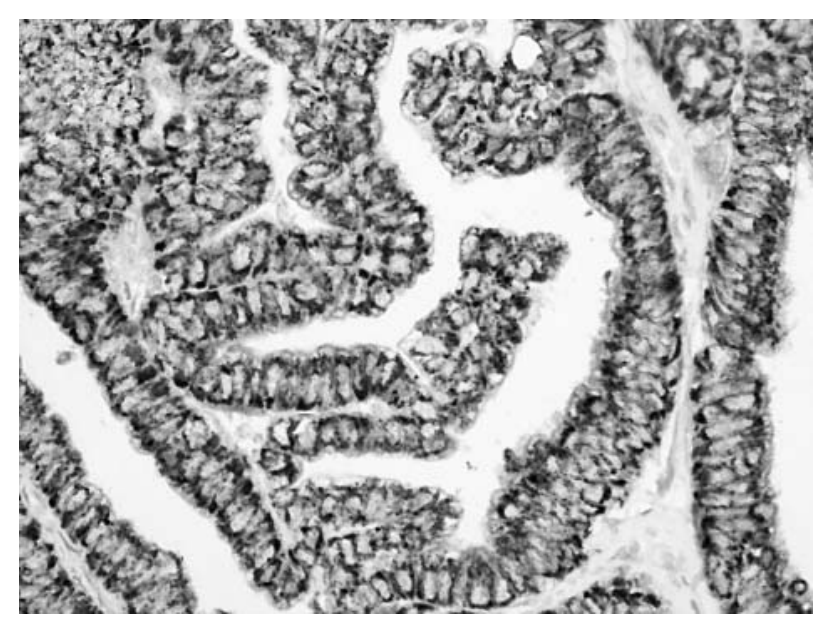

Figure 4 Adenocarcinoma expressing strong and diffuse Hep Par 1 immunoreactivity (immunoperoxidase).

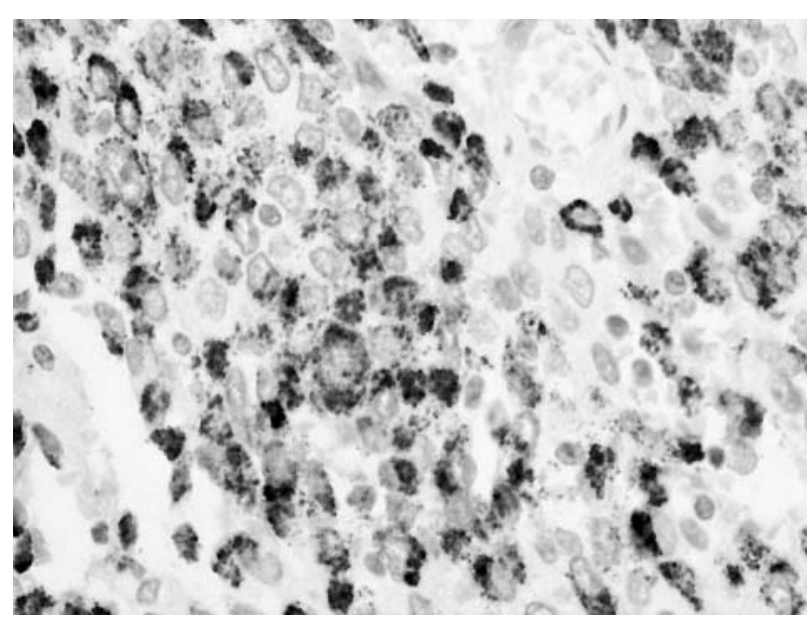

Figure 5 Squamous cell carcinoma expressing strong but patchy Hep Par 1 immunoreactivity (immunoperoxidase).

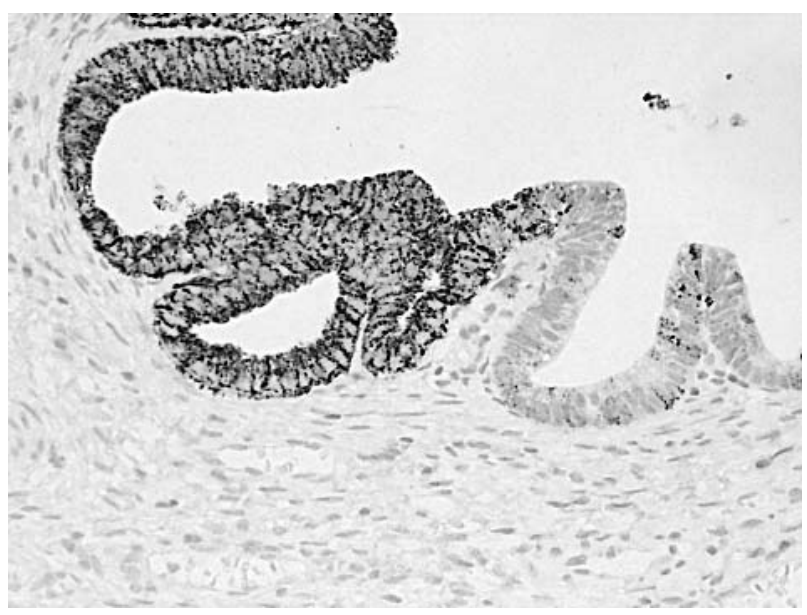

Figure 6 Endocervical adenocarcinoma in situ expressing patchy Hep Par 1 immunoreactivity (immunoperoxidase).

\section{Biological behaviour}

Three of the four Hep Par l positive invasive carcinomas (cases 2, 6 and 7) showed the presence of extensive intravascular tumour emboli; they appeared to have a worse outcome, irrespective of tumour stage at the time of surgery.

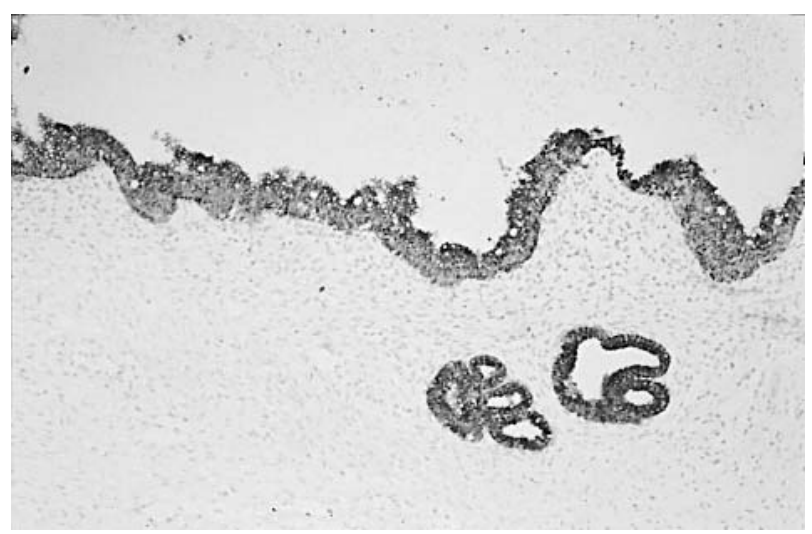

Figure 7 Morphologically normal looking endocervical glands expressing strong Hep Par 1 immunoreactivity (immunoperoxidase). 
Table 2 Hep Par 1 negative cases

\begin{tabular}{|c|c|c|c|c|c|c|c|}
\hline \multirow[b]{2}{*}{ Case } & \multirow[b]{2}{*}{ Tumour type } & \multicolumn{3}{|c|}{$\begin{array}{l}\text { Immunohistochemical markers } \\
\text { (extent of staining) }\end{array}$} & \multicolumn{3}{|c|}{ Clinical correlates } \\
\hline & & AFP & CG & SYN & VI & Stage & Outcome \\
\hline 8 & $A C$ & - & $10 \%$ & Focal & - & $|B|$ & $A+W$ \\
\hline 9 & $A C$ & - & Focal & - & - & $|\mathrm{B}|$ & $A+W$ \\
\hline $10-25$ & SCC & - & - & - & $5 / 16$ & $\begin{array}{l}\text { I (10) } \\
\text { II (4) } \\
\text { III (2) }\end{array}$ & $\begin{array}{l}\mathrm{A}+\mathrm{W} \\
1 \mathrm{Rec}, 1 \text { Met }\end{array}$ \\
\hline $26-27$ & $A C$ & - & - & - & - & $\mid \mathrm{B} 1, \| \mathrm{A}$ & $A+W, N F U$ \\
\hline & $A C+A I S$ & - & - & - & - & $|\mathrm{B}|$ & $\mathrm{A}+\mathrm{W}$ \\
\hline 29 & AlS & - & - & - & - & - & $A+W$ \\
\hline
\end{tabular}

Two of the six patients (cases 5 and 6) with stage IBI disease at the time of diagnosis died of widespread metastatic disease within two years of surgery; one patient was alive with liver metastases (case 1) and the remaining three were alive and well with no evidence of disease. Patient 3 with stage IIIB disease was also alive and well.

\section{AFP expression}

The LCNEC (case 1) was the only sample that expressed AFP, albeit focal $(<5 \%)$ and weak to moderate. Staining was confined to the undifferentiated carcinoma cells and not the Hep Par 1 positive AIS areas. When liver metastases developed four months later, the serum AFP concentration was $4697 \mu \mathrm{g} /$ litre, with corresponding tissue AFP positivity in the fine needle aspiration material of the liver lesions.

\section{Neuroendocrine marker expression}

Three Hep Par 1 positive cases (one each of LCNEC, AC, and AIS) showed the presence of neuroendocrine markers (fig 8). However, there was no apparent histological or topographical correlation between the immunoreactive cells. Vascular invasion was observed only in the LCNEC.

Twenty two of the 29 cases were negative for Hep Par 1 (table 2); they comprised 16 SCCs, four ACs, one AC with AIS, and one AIS. None had hepatoid histomorphology. Two ACs expressed neuroendocrine markers (cases 8 and 9). Five of 21 patients with invasive lesions (all SCCs) showed vascular invasion, with two of them having adverse outcomes-one developed bone metastases two years after initial surgery, whereas the other developed an abdominal wall

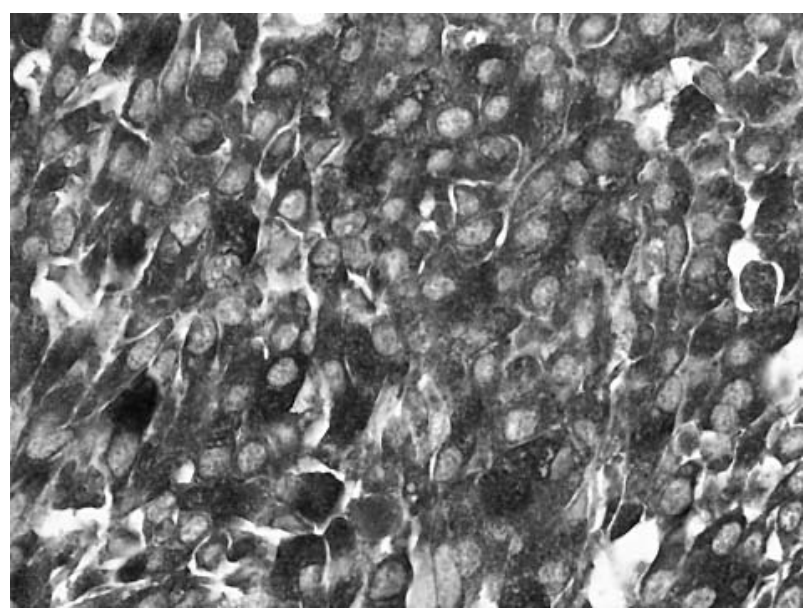

Figure 8 Poorly differentiated adenocarcinoma expressing strong and diffuse chromogranin immunoreactivity (immunoperoxidase). recurrence one year after surgery. One patient was lost to follow up and the remaining patients are alive and well.

Control cases

No Hep Par l staining was detected in the endocervical glands of the 10 non-cancer related hysterectomies.

\section{DISCUSSION}

A large proportion of cervical carcinomas (seven of 29) stained with Hep Par 1. However, only one displayed hepatoid features, although another was a clear cell adenocarcinoma resembling fetal gut, a feature observed in hepatoid gastric carcinomas. ${ }^{17}$ As such, in most instances there was no reason to suspect a hepatoid connection, least of all to stain with Hep Par 1. It was also notable that there was staining of AIS lesions and even normal looking endocervical epithelium.

The Hep Par 1 positive invasive carcinomas in our study showed a higher rate of vascular invasion (three of four) compared with their Hep Par 1 negative counterparts (five of $21)$. In some studies, the incidence of vascular invasion in cervical carcinoma has been reported to be as high as $43 \%$ in stage I and II tumours, ${ }^{33}$ but more commonly in the range of $20-30 \%,{ }^{33}{ }^{34}$ correlating with the data for the Hep Par 1 negative cases $(24 \%)$. Other studies have also noted the propensity of hepatoid carcinomas for vascular permeation. ${ }^{12-14}$ Hence, hepatoid appearance, clear cell features, and/or vascular invasion might be an indicator to stain for Hep Par 1 and AFP.

The overall rate of neuroendocrine marker expression was five of 29. This contrasts with a recent study of cervical carcinoma with synaptophysin expression in only five of 54 cases. ${ }^{35}$

The expression of the gene(s) encoding the Hep Par 1 antigen may result from the genetic instability inherent in cancer cells. Hep Par 1 expression appears to be more prevalent in AIS (three of five) than in invasive carcinoma (four of 27). In addition, in the two cases with both AIS and invasive components, only the AIS components showed Hep Par 1 staining. The acquisition of the Hep Par 1 positive phenotype may be an early event in the sequence of progression from dysplasia of glandular cells through in situ to invasive malignancy-a property that is lost in some cases of AIS as they progressively become invasive. If this is the case, then the morphologically normal looking endocervical glands with Hep Par 1 expression may represent an even earlier genetic mutation, with the acquisition of the Hep Par 1 positive phenotype before the acquisition of dysplastic morphology.

The Hep Par 1 positive invasive tumours in our study had a generally worse outcome than the Hep Par l negative group. This outcome was apparently not associated with hepatoid 
histomorphology or AFP expression, and was independent of tumour stage.

The two patients with neuroendocrine expression only (Hep Par 1 negative) were alive and well with no evidence of disease recurrence at two years of follow up. This differs somewhat from the findings of Chavez-Blanco et al, ${ }^{35}$ who found that their patients with synaptophysin positive cervical carcinomas all relapsed within six months of follow up. In contrast, the two patients with invasive carcinoma who expressed both Hep Par 1 and neuroendocrine markers in the invasive/in situ components (cases 1 and 5) had adverse outcomes, with one patient dying of the disease 2.5 years after initial surgery and the other developing liver metastases. Thus, the coexpression of Hep Par 1 and neuroendocrine markers may herald rapid progression of disease and a poor prognosis, even worse than Hep Par 1 expression alone.

Hep Par 1 expression by carcinomas of the cervix may have diagnostic relevance in the setting of patients with known cervical carcinoma who subsequently develop liver masses. In such cases, the diagnostic differential would be between a primary hepatocellular carcinoma (HCC) and liver metastasis from the primary cervical tumour (case 1). The problem arises when there is a solitary liver mass and the scanty fine needle aspiration (FNA) material shows equivocal cytological features. The usual immunohistochemical panel used to differentiate between metastatic carcinoma and HCC may show Hep Par 1 and even AFP positivity in the metastatic carcinoma cells, thereby compounding the diagnostic dilemma.

"The coexpression of Hep Par 1 and neuroendocrine markers may herald rapid progression of disease and a poor prognosis, even worse than Hep Par 1 expression alone"

In conclusion, Hep Par 1 expression was seen in almost a quarter of the cervical carcinomas studied, covering a spectrum of histological types, including in situ carcinoma. Hep Par 1, with or without neuroendocrine coexpression, is apparently associated with a worse prognosis. Hep Par 1 immunostaining may be useful in selected cases of cervical carcinoma as an adjunct to other commonly assessed parameters, such as vascular invasion, in prognostic determination. Further studies involving larger numbers of cases are required to confirm this observation. Another diagnostic implication that must be entertained, in the light of positive Hep Par 1 staining of cervical carcinoma cells, is during the interpretation of FNA material of liver masses from patients with primary cervical carcinomas-not all Hep Par 1 and AFP positive tumour tissue in the liver is necessarily of hepatic

\section{Take home messages}

- Hep Par 1 is expressed relatively frequently in carcinomas of the cervix and is present in a variety of histological types

- Hep Par 1 expression appears to be associated with more aggressive biological behaviour and a worse prognosis

- Because the uterine cervix is another site that may be positive for Hep Par 1, the use of this antibody in situations of diagnostic difficulty, especially involving lesions within the liver, should be coupled with the knowledge of the range of tissues it may stain origin. Lastly, the diagnostic usefulness, in particular, the specificity of the Hep Par 1 immunostain for its intended tissues (hepatocyte derived) must be re-evaluated. The use of this antibody in situations of diagnostic difficulty must be coupled with the awareness and knowledge of the increasing range of tissue types that it may stain.

\section{ACKNOWLEDGEMENTS}

We thank Mr O C Kee for his technical assistance with immunohistochemistry and Mr T T Chok for his assistance with photography.

\section{Authors' affiliations}

T P Thamboo, A Wee, Department of Pathology, National University of Singapore, National University Hospital, 5 Lower Kent Ridge Road, Singapore 119074, Republic of Singapore

\section{REFERENCES}

1 Wennerberg AE, Nalesnik MA, Coleman WB. Hepatocyte Paraffin 1: a monoclonal antibody that reacts with hepatocytes and can be used for differential diagnosis of hepatic tumors. Am J Pathol 1993;143:1050-4.

2 Minervini MI, Demetris AJ, Lee RG, et al. Utilization of hepatocyte-specific antibody in the immunocytochemical evaluation of liver tumors. Mod Pathol 1997; 10:686-92.

3 Leong AS-Y, Sormunen RT, Tsui WMS, et al. Hep Par 1 and selected antibodies in the immunohistological distinction of hepatocellular carcinoma from cholangiocarcinoma, combined tumours and metastatic carcinoma. Histopathology 1998;33:318-24.

4 Kumagai I, Masuda T, Sato S-I, et al. Immunoreactivity to monoclonal antibody, Hep Par 1, in human hepatocellular carcinomas according to histopathological grade and histological pattern. Hepatol Res 2001;20:312-19.

5 Zimmerman RL, Burke MA, Young NA, et al. Diagnostic value of hepatocyte paraffin 1 antibody to discriminate hepatocellular carcinoma from metastatic carcinoma in fine-needle aspiration biopsies of the liver. Cancer 2001;93:288-91.

6 Siddiqui MT, Saboorian MH, Gokaslan ST, et al. Diagnostic utility of the HepParl antibody to differentiate hepatocellular carcinoma from metastatic carcinoma in fine-needle aspiration samples. Cancer 2002;96:49-52.

7 Morrison C, Marsh Jr W, Frankel WL. A comparison of CDIO to PCEA, MOC31 and Hepatocyte for the distinction of malignant tumors in the liver. Mod Pathol 2002;15:1279-87.

8 Fan Z, van de Rijn M, Montgomery K, et al. Hep Par 1 antibody stain for the differential diagnosis of hepatocellular carcinoma: 676 tumors tested using tissue microarrays and conventional tissue sections. Mod Pathol 2003; 16:137-44

9 Chu PG, Ishizawa S, Wu E, et al. Hepatocyte antigen as a marker of hepatocellular carcinoma. An immunohistochemical comparison to carcinoembryonic antigen, CD10 and alpha-fetoprotein. Am J Surg Pathol 2002;26:978-88

10 Lau SK, Prakash S, Geller SA, et al. Comparative immunohistochemical profile of hepatocellular carcinoma, cholangiocarcinoma and metastatic carcinoma. Hum Pathol 2002;33:1175-81.

11 Roberts CC, Colby TV, Batts KP. Carcinoma of the stomach with hepatocytic differentiation (hepatoid adenocarcinoma). Mayo Clin Proc 1997:72: 1154-60.

12 Ishikura H, Kishimoto T, Andachi H, et al. Gastrointestinal hepatoid adenocarcinoma: venous permeation and mimicry of hepatocellular carcinoma, a report of four cases. Histopathology 1997;31:47-54.

13 Li X, Zhang D, Le M. Histopathological and immunohistochemical studies in hepatoid adenocarcinomas of the stomach [In Chinese]. Zhonghua Bing Li Xue Za Zhi 1996:25:276-9.

14 Nagai E, Ueyama T, Yao T, et al. Hepatoid adenocarcinoma of the stomach. A clinicopathologic and immunohistochemical analysis. Cancer 1993:72:1827-35.

15 Ishikura H, Fukasawa Y, Ogasawara K, et al. An AFP-producing gastric carcinoma with features of hepatic differentiation. A case report. Cancer 1985;56:840-8.

16 Matsunou H, Konishi F, Jalal RE, et al. Alpha-fetoprotein-producing gastric carcinoma with enteroblastic differentiation. Cancer 1994:73:534-40.

17 Morinaga S, Takahashi Y. Primary hepatocellular carcinoma and hepatoid adenocarcinoma of the stomach with liver metastasis: an unusual association. Jpn J Clin Oncol 1996;26:258-63.

18 Rassidakis GZ, Delladetsima JK, Letsos SP, et al. Hepatoid adenocarcinoma of the stomach with extensive neuroendocrine differentiation and a coexisting carcinoid tumour. Histopathology 1998;33:186-8.

19 Maitra A, Murakata LA, Albores-Saavedra J. Immunoreactivity for hepatocyte paraffin 1 antibody in hepatoid adenocarcinomas of the gastrointestinal tract. Am J Clin Pathol 2001;115:689-94.

20 Hiroshima K, lyoda A, Toyozaki T, et al. Alpha-fetoprotein-producing lung carcinoma: report of three cases. Pathol Int 2002;52:46-53.

21 Kimura N, Ghandur-Mnaymen L. An immunohistochemical study of keratin, carcinoembryonic antigen, human chorionic gonadotropin and alphafetoprotein in lung cancer. Tohoku J Exp Med 1985;145:23-38. 
22 Yamamoto R, Ishikura $\mathrm{H}$, Azuma $\mathrm{M}$, et al. Alpha-fetoprotein production by a hepatoid adenocarcinoma of the uterus. J Clin Pathol 1996;49:420-2.

23 Hoshida Y, Nagakawa T, Mano S, et al. Hepatoid adenocarcinoma of the endometrium associated with alpha-fetoprotein production. Int J Gynecol Pathol 1996; 15:266-9.

24 Toyoda H, Hirai T, Ischii E. Alpha-fetoprotein producing uterine corpus carcinoma: a hepatoid adenocarcinoma of the endometrium. Pathol Int 2000;50:847-52.

25 Adams SF, Yamada SD, Montag A, et al. An alpha-fetoprotein-producing hepatoid adenocarcinoma of the endometrium. Gynecol Oncol 2001;83:418-21.

26 Shintaku M, Kariya M, Shime $H$, et al. Adenocarcinoma of the uterine cervix with choriocarcinomatous and hepatoid differentiation: report of a case. Int J Gynecol Pathol 2000;19:174-8.

27 Lopez-Beltran A, Luque RJ, Quintero A, et al. Hepatoid adenocarcinoma of the urinary bladder. Virchows Arch 2003;442:381-7.

28 Burgues O, Ferrer J, Navarro S, et al. Hepatoid adenocarcinoma of the urinary bladder. An unusual neoplasm. Virchows Arch 1999:435:71-5.
29 Yamada $K$, Fuijoka $Y$, Ebihara $Y$, et al Alpha-fetoprotein producing undifferentiated carcinoma of the bladder. J Urol 1994;152:958-60.

30 Wee A, Thamboo TP, Thomas A. Alpha-fetoprotein-producing liver carcinomas of primary extrahepatic origin: fine needle aspiration biopsy experience in 2 cases. Acta Cytol 2003:47:799-808.

31 Scully RE, Bonfiglio TA, Kurman RJ, et al. Histological typing of female genital tract tumours, 2nd ed. Berlin: Springer-Verlag, 1994 (World Health Organisation, International histological classification of tumours series)

32 Greene FL, Page DL, Fleming ID, et al. AJCC cancer staging handbook, 6th ed. New York: Springer Verlag, 2002.

33 Burghardt E, Baltzer J, Tulusan AH, et al. Results of surgical treatment of 1028 cervical cancers studied with volumetry. Cancer 1992;70:648-55.

34 Zaino RJ, Ward S, Delgado G, et al. Histopathologic predictors of the behavior of surgically treated stage IB squamous cell carcinoma of the cervix. A gynecologic oncology group study. Cancer 1992;69:1750-8.

35 Chavez-Blanco A, Taja-Chayeb L, Cetina L, et al. Neuroendocrine marker expression in cervical carcinomas of non-small cell type. Int J Gynecol Pathol 2002;21:368-74.

\section{Clinical Evidence - Call for contributors}

Clinical Evidence is a regularly updated evidence based journal available worldwide both as a paper version and on the internet. Clinical Evidence needs to recruit a number of new contributors. Contributors are health care professionals or epidemiologists with experience in evidence based medicine and the ability to write in a concise and structured way.

\section{Currently, we are interested in finding contributors with an interest in} the following clinical areas:

Altitude sickness; Autism; Basal cell carcinoma; Breast feeding; Carbon monoxide poisoning; Cervical cancer; Cystic fibrosis; Ectopic pregnancy; Grief/bereavement; Halitosis; Hodgkins disease; Infectious mononucleosis (glandular fever); Kidney stones; Malignant melanoma (metastatic); Mesothelioma; Myeloma; Ovarian cyst; Pancreatitis (acute); Pancreatitis (chronic); Polymyalgia rheumatica; Post-partum haemorrhage; Pulmonary embolism; Recurrent miscarriage; Repetitive strain injury; Scoliosis; Seasonal affective disorder; Squint; Systemic lupus erythematosus; Testicular cancer; Varicocele; Viral meningitis; Vitiligo However, we are always looking for others, so do not let this list discourage you.

Being a contributor involves:

- Appraising the results of literature searches (performed by our Information Specialists) to identify high quality evidence for inclusion in the journal.

- Writing to a highly structured template (about 2000-3000 words), using evidence from selected studies, within 6-8 weeks of receiving the literature search results.

- Working with Clinical Evidence Editors to ensure that the text meets rigorous epidemiological and style standards.

- Updating the text every eight months to incorporate new evidence.

- Expanding the topic to include new questions once every 12-18 months.

If you would like to become a contributor for Clinical Evidence or require more information about what this involves please send your contact details and a copy of your CV, clearly stating the clinical area you are interested in, to Claire Folkes (cfolkes@bmigroup.com).

\section{Call for peer reviewers}

Clinical Evidence also needs to recruit a number of new peer reviewers specifically with an interest in the clinical areas stated above, and also others related to general practice. Peer reviewers are health care professionals or epidemiologists with experience in evidence based medicine. As a peer reviewer you would be asked for your views on the clinical relevance, validity, and accessibility of specific topics within the journal, and their usefulness to the intended audience (international generalists and health care professionals, possibly with limited statistical knowledge). Topics are usually 2000-3000 words in length and we would ask you to review between 2-5 topics per year. The peer review process takes place throughout the year, and our turnaround time for each review is ideally 10-14 days.

If you are interested in becoming a peer reviewer for Clinical Evidence, please complete the peer review questionnaire at www.clinicalevidence.com or contact Claire Folkes(cfolkes@bmigroup.com). 